\title{
Active Methodologies as Investigative Practices in the Mathematics Teaching
}

\author{
Iran Abreu Mendes ${ }^{1,2^{*}}$ \\ ${ }^{1}$ Universidade Federal do Pará, BRASIL \\ 2 Programa de Pós-graduação em Educação em Ciências e Matemáticas - UFPA, BRASIL \\ * CORRESPONDENCE: $\square$ iamendes1@gmail.com
}

\begin{abstract}
In this article I present some notes and reflections on possible ways to be adopted in teaching practice in Mathematics for the incorporation of meanings in teaching and learning of school mathematics in face of the cultural diversity in which the school is situated and constituted in the 21st century through the perspective of globalization. It is a matter of betting on the potential of classroom interactions, subsidized by practices based on methodological approaches that prioritize the direct action of students in the learning process. This is a reflection on the results obtained in experiments carried out in the training of mathematics teachers which were analyzed from authors who base proposals for teaching mathematics through investigative actions to reach learning. These experiences were part of the studies that I have developed since the 1990s and have shown how this approach to teaching mathematics in Basic Education and teacher training contributes decisively to the autonomous learning of those involved.
\end{abstract}

Keywords: active methodologies. mathematics teaching, school mathematics

\section{INTRODUCTION}

In this article I will present a few notes and reflections on possible ways to be adopted in the teaching practice for the incorporation of meanings in the teaching and learning of school mathematics in face of the cultural diversity in which the school is situated and constituted. It is a matter of betting on the potential of classroom interactions, subsidized by practices based on methodological approaches that prioritize the direct action of students in the learning process.

From this perspective, the teaching problem raises some questions such as: what methodologies should one propose to educate the students so that they can live in a learning society like the present one? What teaching methodologies should one propose to the school aiming the social transformation in this learning society? Why these methodologies? In what way does the action become the central focus of these methodologies and implies the exercise of active methodologies?

To think about this subject, I present initially two aphorisms about teaching and learning. The first one proposes that "Teaching is something for a ready world" and the second one opposes the first, assuring that "Learning is something for a world in continuous construction". Therefore, it is necessary to rethink a way of teaching that also takes into account the continuous construction of understandings about the world. Let us see, then, some considerations about each of these aphorisms. When we mention that teaching is something for a ready world, we start from an understanding of teaching as a fundamental element in the educational process operationalized in the school to insert students into a model that is already given and consolidated.

Article History: Received 25 January $2019 \bullet$ Revised 17 February $2019 \bullet$ Accepted 21 February 2019

(C) 2019 by the authors; licensee Modestum Ltd., UK. Open Access terms of the Creative Commons Attribution 4.0 International License (http://creativecommons.org/licenses/by/4.0/) apply. The license permits unrestricted use, distribution, and reproduction in any medium, on the condition that users give exact credit to the original author(s) and the source, provide a link to the Creative Commons license, and indicate if they made any changes. 


\section{\#1 TEACHING IS SOMETHING FOR A READY WORLD}

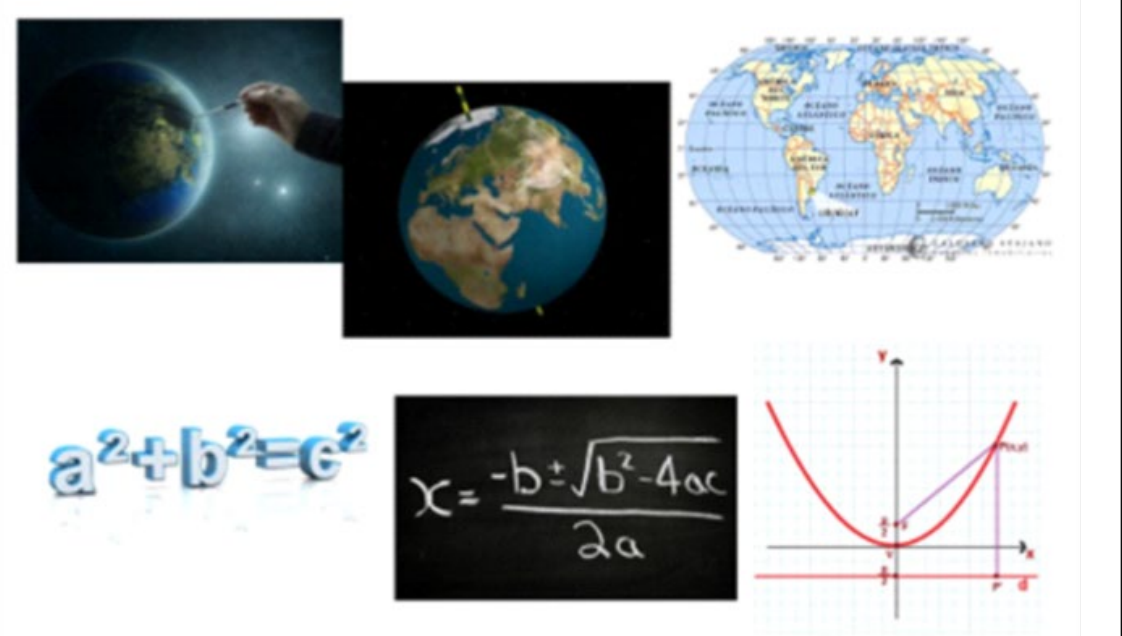

Figure 1. Elaborated by the author

As long as we are aware of teaching as a verb that expresses the action we wish to undertake in this ready world, we cannot act pedagogically on a defined world, but on a world in continuous construction.

This first aphorism exemplifies well two aspects related to a ready approach in mathematics teaching. When we present the subjects in this way, it seems that nothing was built, that is, it transpires that things have always been like this. Everything seems informed in a perfectly structured way so that the student can appropriate the information and reproduce it whenever necessary. There is no questioning or gap in the construction. Everything is perfect.

Contrary to this understanding about teaching, Anastasiou (2014) make their considerations about teaching and learning. Anastasiou and Alves (2007, p. 18), mentioning that

the verb to teach, from the Latin insignare means to mark with a sign, which should be of life, search and awakening to knowledge. In the classroom reality, there may be an understanding, or not, of the intended content, the adherence or not to more evolved ways of thinking, the mobilization, or not, for other actions of study and learning.

According to the emphasis given by the authors to the term, to teach means, therefore, to direct so that life can be given to that which one intends to know or to make known, for it is a matter of awakening in the sense of clarifying for understanding. Still on the subject, the authors make other important considerations emphasizing that

like other action verbs, teaching contains in itself two dimensions: an intentional use and an outcome, that is, the intention of teaching and the execution of that intended object. So, if I have explained a school content, but the student did not appropriate it, can I say that I have taught him something or only fulfilled a part of the process? Even if I have a sincere intention to teach, if the goal (the understanding, the appropriation of content by the student) is not fully realized, as would be necessary or expected in order to continue the student's school path, can I say that I have taught? Will I have fulfilled the two dimensions intended in the action of teaching? (Anastasiou \& Alves, 2007, p.18).

Such considerations make us imagine the dimensions of the object that one intends to make known and the implications of connections reached by those involved in the act of knowing through the actions implemented in order to achieve the pre-established purposes, by which we direct the act of knowing. It is, therefore, an interconnected relationship between what is planned, done and reflected on what has been or can be achieved. Thus one can impute dimensional levels of scope of what was the planned achievement, that is to go as far as possible and go through possible dimensions of what one wants to know, that is to say, the world in continuous construction that can be apprehended. 


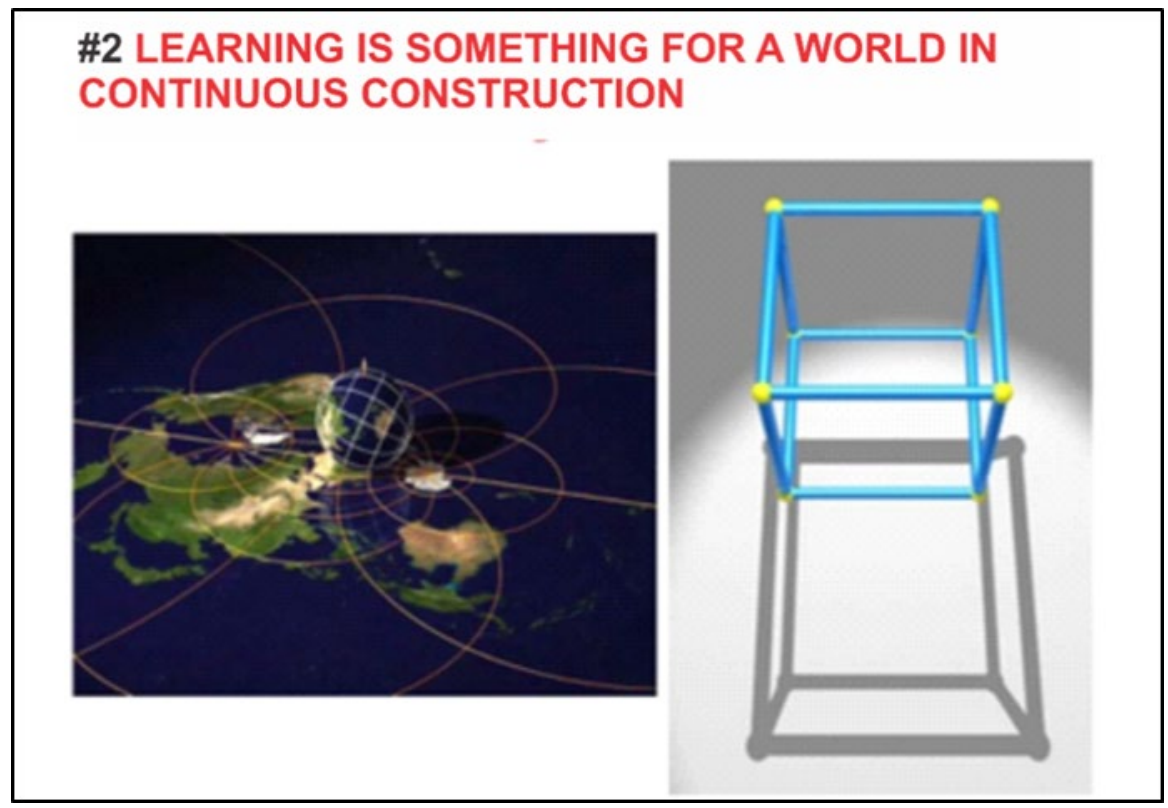

Figure 2. Elaborated by the author

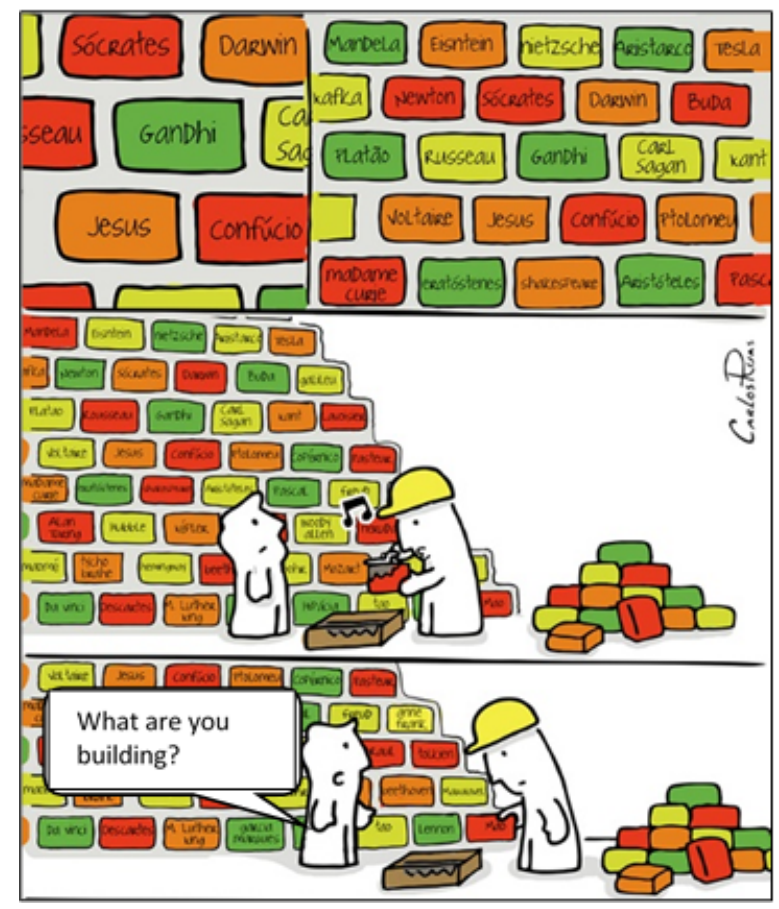

Figure 3. Image by Carlos Ruas

In the case of the aphorism learning is something for a world in continuous construction, it means that according to the substantive matter used in this construction, we erect a more solid or more fragile structure in that construction, that is, such a construction in continuous transformation depends directly on the substances used in its structuring and in the procedural refinement of this construction. Therefore, learning is an inexhaustible process that perfects itself in sociocultural dynamics based on the different reference points taken as instruments for the understanding of the world.

The reflections previously discussed lead us to think figuratively about the fact that every existing image is a reflection of any reality we learn from the world i.e. the level of possible learning, but in a constant improving process, which depends directly of what we understand as substances that are combined for the organization of the structures of our intellectual construction. 


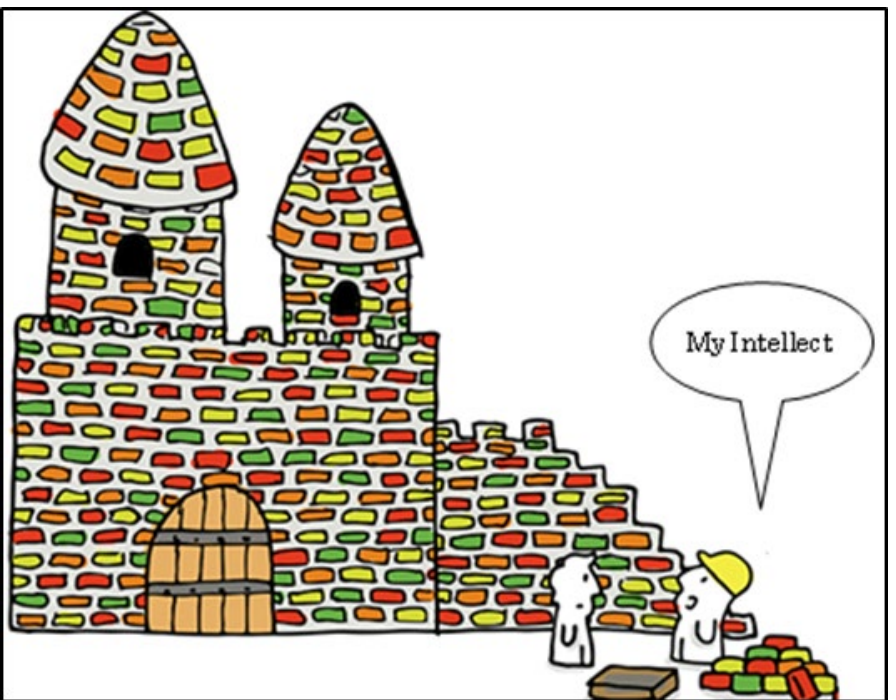

Figure 4. Image by Carlos Ruas

\section{WHAT ARE THE SUBSTANCES OF THE STRUCTURES OF THIS INTELLECTUAL CONSTRUCTION?}

When we chose the image of the construction we consider that in order to erect it, we need to plan and build a structure to support this construction. In the case of intellectual construction, the objects of thought are continually constructed based on the cognitive interactions established by the thinking subject, from combinations and creations originated from a general culture connected with a scientific culture which is embodied in cultural diversity and social practices, and historically produced and kept alive through reinvention, social and school reformulations, originating the modes, senses and meanings attributed to knowledge that is imagined, produced, materialized and used socially.

According to what Snow (1995) discusses in his book The two cultures and a second reading, the term culture contains plural meanings that denote ambiguities and deep senses in every situation in which it is used. On the one hand refers to intellectual development, development of the mind. However, it is necessary to understand that in its broad senses the term refers also to cultivation, that is, to the process of harmonious development of the qualities and faculties that characterize our humanity. For the author, culture is a term also used in Anthropology to denote a group of people living in the same environment, linked by common habits, common postulates and a common way of life ".

In this case, Farias and Mendes (2014) assert that in our social institution we understand culture as a set of knowledge, actions, rules, beliefs, strategies and myths, one that is expressed by diversity, creativity and innovation, always unfinished. In this way we are marked, simultaneously, by the unity and diversity of culture. Thus we are also subjects who reorganize themselves through the brain-mind-environment symbiosis implied by the sociodynamics of culture, as emphasized by Abraham Moles (2012), in arguing that human knowledge is originated by the objects and processes established in the culture as a dynamic reaction to everything that is proposed by the environment and operationalized through the problematization of the context. Therefore, it is important to emphasize that, despite being part of a complex system that constitutes the environment, human society is distinguished from other animals by the faculty of producing culture and building history.

Considering the contributions of Anthropology to Education as a contribution to teacher training, our primary purpose is to start from the idea of culture as a concept that is transversal to the different areas of knowledge and as an important concept notion in the integral formation of any professional in the Educational field, with the perspective of establishing better relationships between teachers and future teachers with their students, so as to promote possibilities for them to relate better to the diversity of expressions in the classroom everyday (Farias \& Mendes, 2014).

In view of the foregoing paragraphs, an intermediate question arises about the central theme of this article: what is the relationship that exists between cultural diversity and education in contemporary society and the 
need to return to school the use of teaching methods centered on practices involved in the action of the learning subject?

\section{ON CULTURAL DIVERSITY IN SCHOOL AND PEDAGOGIES OF SITUATION IN TEACHER EDUCATION}

Regarding the relations between cultural diversity and the current educational process in contemporary society, we consider the connections between words and their reflections in educational practices to be extremely important. This is because, according to Moles (2012), in the process of institutionalizing human society, culture stands out as a way of perceiving individual and collective identity, that is, the one and the multiple, the singular and the planetary plural of our society, incurring, therefore, in the diversity and in the constitution of cultural diversity.

With regards to cultural dynamics and its implication in society, several authors emphasize that it is a matter of the dynamics of cultural encounters, in which social practices are established through an interchangeable dynamics of beliefs, values and repertoires in their social diffusion that, being operated in varied processes and modalities of cultural messages, are of decisive social importance. It is in this social interaction that multiple languages emerge in an attempt to validate expressions of cultural messages, so as to ground the senses of culture as something from daily life and thus enable intellectual creation.

And in this movement there is a kind of submersion of sociocultural creativity by formalized intellectual knowledge, in which the validation ballast is established, formalized in this socio-interaction and in the sociocultural movements that operate the expansion of the relations between formal and informal knowledge. As is the case today, we can cite the technological and informational revolutions of the contemporary world and the networked society as environments in which the socialization of information and the treatment of it operate in the production of knowledge in an environment continuously interconnected such as in social networks, in virtual learning environments, that is, in informational communication systems in general.

How can we think of a mathematics teaching in which these interactions enable the integration of knowledge, the social interaction of teachers and students, the interaction between students in search of the production of knowledge, learning and educational training? How do we situate ourselves around this cultural diversity in our actions of teaching mathematics?

If we consider the cultural diversity that has historically spawned creations and discoveries in mathematics, it becomes more comprehensive to think about ways of incorporating this diversity into mathematics teaching, for the need to calculate, measure, compare, and demonstrate has always been present in cultures in search of cognitive truths and the re-effectuation of the mathematical activities and in the idealization of the mathematical objects and their reflections, originating knowledge and practices that have strengthened the ways of teaching and learning Mathematics. However, with each historical moment we experience, we realize that our challenges as teachers who work in Mathematics teacher training and even in School Education grow larger.

All this historically established movement in Mathematics and in its teaching reflects the process of construction of mathematical objectivities in cultural subjectivities, that is, a continuous and dynamic attempt to create, recreate, adapt and proceed searches for suitable methodologies to be processed in the teaching for undergraduate degrees in Mathematics. However, when we ask teachers if they put into practice the teaching methodologies they have learned in their undergraduate education in their Mathematics classes and how do they do it, we obtained contradictory, empty and often accusative answers that, as far as didactic goes, the did not take anything from their training into their teaching.

Regarding the ways in which these teaching methodologies are practiced, we made a survey with students from the Mathematics teacher training course and with graduated teachers, in order to find out how do they use such methodologies in school, what do these methodologies are for, why should they be addressed in the Mathematics degree-obtaining course, what actions should be taken, how they should be operationalized in or outside the classroom, and how a creative environment could be created for that practice. The participants in the survey responded that these practices can only be productively operationalized in the training of Mathematics teachers and in Elementary Education classes if both the teacher and the students act simultaneously as instigators and learners, that is, if both of them exercise the search of launching themselves into challenges and solutions for each challenge, without losing sight of the interactive dialogue that can 


\title{
On the teaching methodologies implemented in teacher training courses
}

\author{
Which methodologies?
}

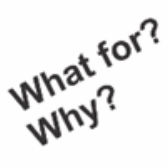

Environment: creative?
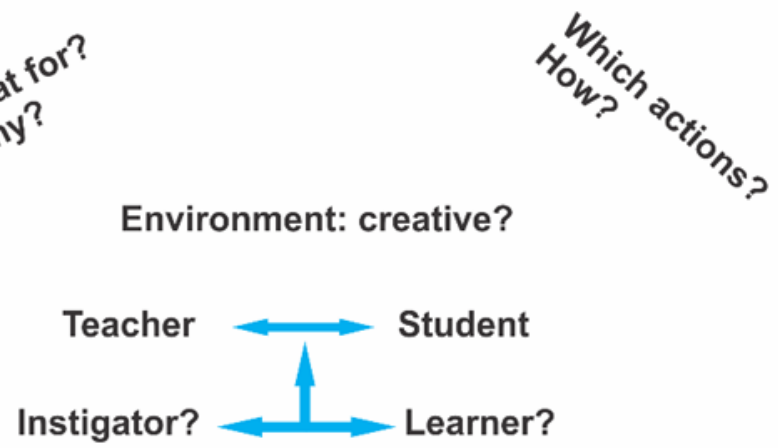

Figure 5. Elaborated by the author

materialize the dynamics of the cultural encounter in the classroom and the expansion of the reflections about the objects of knowledge.

The challenges of teachers who teach mathematics are, therefore, to take these methodologies in search of connections between formal and informal knowledge. But what are these methodologies? What are they about? How to implement them in the classroom? What are their foundations?

Regarding some principles that base methodologies with these characteristics, Barret $(1986 ; 1992)$ states that in order to carry out such practices a teacher must have human, psychological and animation qualities (dynamization), that is, it should receive, listen, and have the necessary sensitivity to manage situations and analyze them, as well as seek to reconcile respect for individual freedom with collective freedom, through its practice, to enhance meaningful learning (Martins, 2002).

Similarly, Barret (1992) asserts that this teacher should exercise a triple role as an animator-observerparticipant, as well as being a transmitter and receiver simultaneously, as a reflecting mirror of his / her student group, its catalyst, its common place or its common denominator. In this manner, the author argues that teaching programs, didactic-pedagogical materials and actions to support teachers' training move from a humanistic perspective that values and enriches the subject in formation, and promotes their development of skills, abilities and professional attitudes that lead them to be a manager of learning environments favorable to learning and to exercise their apprehension of unique situations for incorporation into the teaching process.

If we consider what Barret (1992) calls the Situation Pedagogy, in which the knowledge involved in this pedagogy are knowledge, know-how, knowledge to be entertainer-observer-participant in the classroom during teaching and learning activities will be It is therefore possible to admit that such professional attributes when acquired in a formative process and experienced in reflected practices during formative actions such as moments related to investigative actions that may allow the teacher in formation another way of understanding and developing professionally.

Another question is: how can such referrals materialize in practices related to teacher training in active and investigative methodologies?

\section{FROM THE ACTIVE AND INVESTIGATIVE METHODOLOGIES: ITS AIMS AND PROCEDURES}

With regard to the so-called active methodologies, we consider that they have the potential to arouse curiosity, to the extent that the students insert themselves in the act of theorizing and bring new elements, not yet considered, to the classes or to the teacher's own perspective. One of the purposes of these methodologies is to promote students' autonomy in and out of the classroom so that they learn to deal with materials, challenging situations and diverse ideas in a personal way, so as to learn to question the objects of 


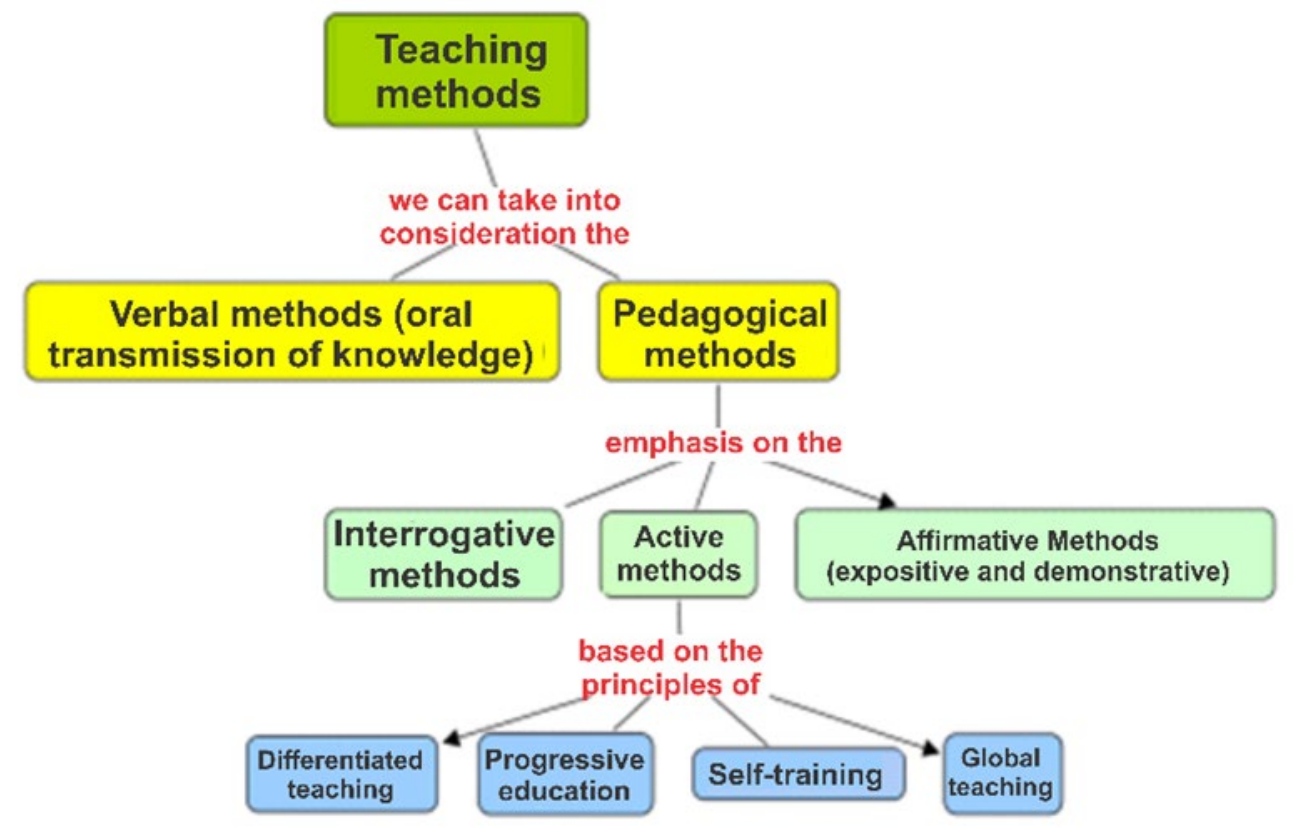

Figure 6. Elaborated by the author

knowledge, to reformulate existing knowledge and experience new ways of understanding, explaining and discussing their ideas.

These methodologies are based on principles and strategies of teaching and searching for learning through interrogative methods, assets that are based on a differentiated teaching, in a process of progressive education that presupposes the self-training of the learner and the development of a global education on the part of the teacher.

They should motivate the autonomy and strengthen the student's perception in the problematization of situations involved in the school program, in the choice of aspects of school contents, in the possible ways for the development of answers or solutions to the problems that present themselves, creative alternatives for the conclusion of the study or research, among other possibilities.

Regarding the autonomy of the learner, active methodologies take into account the development of students' self-confidence in order to develop processes of problematization and learning as intrinsic factors of this learning process, given that this process recognizes the student as the main agent of learning and thus allows for the development of the humanization of learning (active learning), according to John Dewey (2007), Jerome Bruner (1996), David Ausubel (1978), Paulo Freire (1997) and Lave; Wenger (1991). In this way, active learning occurs when the student interacts with the subject he or she is studying and is encouraged to construct knowledge rather than receiving it passively.

It is, therefore, a method of teaching focused on the student and in the development of their active skills and competences for the investigation and construction of their mathematical knowledge based on sociointerational actions carried out inside and outside the classroom, always taking into consideration the context of socio-cultural diversity present in the school environment, represented by the different students and their social histories.

In our experiences we generally practice two modalities of procedural approaches to teaching based on theoretical principles that establish a connection with active methodologies: one that emphasizes learning based on problematizations of the sociocultural objects and another that is materialized in the planning, execution and evaluation of projects of thematic research, also focused on objects of the sociocultural context.

In these teaching methodologies the interactive processes of studies, researches, analysis' and individual or collective decisions are established with the purpose of having the students exercise the search for solutions to one or more problems pointed out by the teacher or selected by the students themselves. In this process the teacher acts as a guiding counselor who directs the student to accomplish researches, reflect and decide for himself what he has to do to achieve the proposed objectives and identify mathematical relationships in the exploration of the investigated objects (Borasi, 1992). 
The didactic procedures are based on multiple ways of conducting individual and collective learning processes, in that they use the real or simulated experiences practiced inside and outside the classroom, with the intention of creating conditions to solve, successfully, the challenges arising from the essential activities of socio-cultural practice, in different contexts.

Active methodologies use problematization as a teaching strategy in search of students' learning, with the objective of reaching and motivating them, because, when facing the problematization presented to them, they are asked to stop, examine, reflect, relate it to their relationships and sociocultural interactions and try to resignify their findings through mathematical relationships. Likewise, problematization may put the student in closer contact with information so as to enable them to produce meaningful knowledge, mainly for the purpose of solving impasses and promoting their own development.

Therefore, learning through thematic research, problematization, or through the solution of open problems concerning mathematics or any other area of knowledge is one of the possibilities for active involvement of the students in their own training process.

However, our experiences in teaching and research point out that in this movement of sociocognitive and cultural exploration of objects in search of mathematical connections, we consider that some verbs are a priority to be conjugated and lived in active methodologies, among which we highlight: to read, to write (to type), to ask, to discuss, to locate and to solve problems, to develop projects, to carry out mental tasks of analysis, synthesis and evaluation and, finally, to think reflexively about everything one does.

As contributions of active and investigative methodologies we can highlight that they increase the possibilities of apprehending a greater volume of meta-mathematical knowledge in their relations to the objects of culture, science and technologies, as well as amplify the retention of information for a longer time, and strengthen the understanding and use of critical and analytical knowledge and reasoning in new situations that may challenge students inside and outside the classroom. They also contribute to increase the student's ability to intervene in contexts of uncertainties and complexities, based on the developed autonomy and on the satisfaction and pleasure in seeking solutions to the problems one faces.

Besides these, one also assumes that they improve the development of reality observation skills towards a process of theorization of the world and amplification of the exercise of elaborating hypothesis' on problematic situations in search of more appropriate solutions to the proposed problems. It means, therefore, an amplified exercise on the relation of reality-knowledge-reality, since it implies in the capacity to perceive connections between the study of reality, the organization and application of knowledge, inside and outside the classroom, during the didactic actions developed by the teacher in his or her teaching activities.

\section{HOW TO PRACTICE THESE METHODOLOGIES IN THE CLASSROOM?}

The flipped classroom is seen as a great innovation in the learning process. As the name itself suggests, it is the teaching method through which the organization logic in a classroom is indeed completely flipped.

One possibility of putting these methodologies into practice in the classroom is by changing the ways and habits of the students and the context of the classroom, that is, by means of a process of inversion of the actions of the actors of the school activities - the teacher and the students. In this sense, the teacher should select the activities to be assigned so that the students read, develop and reflect in advance at home or in any other place they wish, provided they exercise research and reflective problem-making as well as other previous studies related to the subject that they need or intend to actively investigate. In this way, it is to be expected that they are previously prepared to get involved in deepening their knowledge on the subject, thus being able to return to the classroom to discuss the theme with the whole class. Then the teacher can propose and discuss principles and methods of work with the students, so that he or she can later guide them in the interactive exploration with materials such as videos, texts, games, TV programs, magazines, books, etc.

In this movement, it is important for students to be encouraged to work in groups (preferably doubles or trios) and to use all handcrafted or manufactured instruments that they consider to be technologically appropriate to enrich the measuring of information. Thus, the teacher should promote forums and encourage debates among students and suggest that they create interesting questions to discuss in the classroom. We also suggest that teachers try to always innovate and share the positive results of his or her good practices among their fellow teachers, as well as organize an evaluation system that is consistent with the principles and methods adopted in this research practice with the students. It should also explain the process to the parents and the school, to avoid objections. 


\section{The context of these active methodologies}

\section{Environment of active learning}

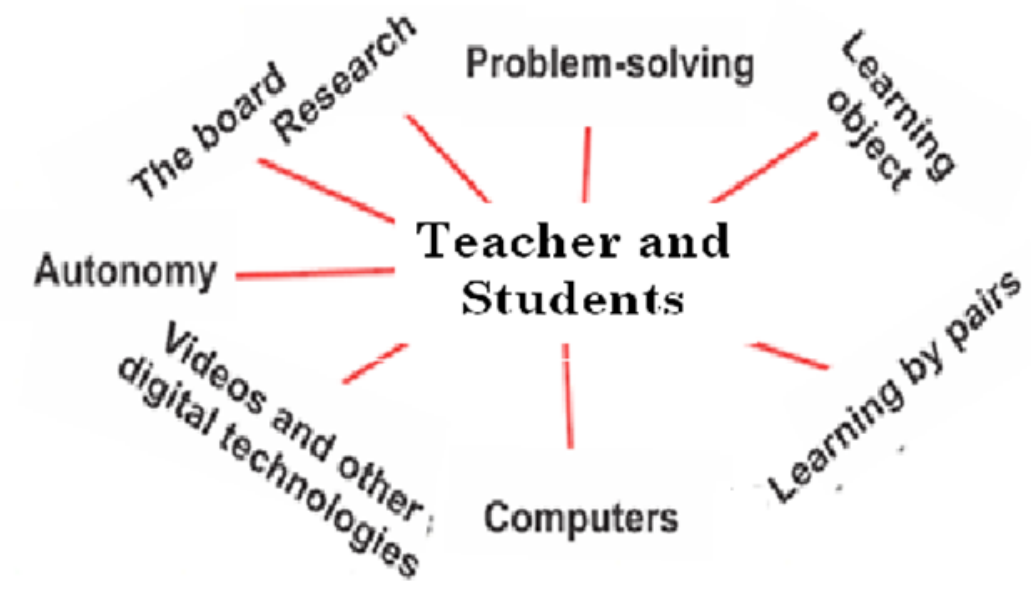

Figure 7. Elaborated by the author

But after all, what are these methodologies? In this respect we can first assert that these teaching methodologies must always be associated with research in order to achieve learning. They also require a mode of insertion that presupposes an active learning environment that involves the teacher, the research, the problematization, and the materials and instruments available at the school such as the classroom board, the computer, video, so that everyone jointly conforms to an outline of the construction of the learning object that will converge to the autonomy of the learner (student), with emphasis on learning through continuous social interaction in the classroom and by the incorporation of the cultural diversity of the classroom. However, what do you expect from the teacher in the methodologies?

It is expected that in this investigative process of learning, mediated by the sociointeraction in the classroom and by problematization in action, it is possible for the teacher to invest in a process of training and self-training, in order to be able to study and to experiment in strategies of oriented teaching in search of learning that is targeted by active methodologies, in which the exchange of ideas and experiences between the students and the teacher contribute to have everyone learn with the process and the results. In this sense, it is important that the teacher elaborates in detail his/her teaching plan with the focus on the extent of the student's learning. However, the student's co-responsibility in the whole teaching and learning process should not be ignored, since that, by committing to his/her learning, the student must invest in constructive relationships with everyone in his class.

On the other hand the teacher needs to guide the student in carrying out the activities required by the teaching strategies so that he/she can achieve their learning, use technologies that help this process, achieve his evaluation and thus provide feedback to those involved. However, the commitment of the student in a comprehensive learning process, through choice and interest, is an essential condition to expand their possibilities of exercising freedom and autonomy in making decisions at different moments in the process they are experiencing, preparing themselves for future professional practice.

\section{ACTIVE AND INVESTIGATIVE METHODOLOGIES IN MATHEMATICS EDUCATION (AIMME)}

In our proposal, active and investigative methodologies in Mathematics Education (AIMME) have the potential to awaken scientific curiosity, problematizing attitude, studying and learning autonomy through research, to the extent that students question reality and problematize situations, insert themselves in theorizing and bring new elements, not yet considered during the classes or in the teacher's own perspective. The AIMME can motivate autonomy and strengthen the students' perception in the problematization of situations involved in the school programming, in the choice of aspects of study contents, in the possible 
pathways for the development of answers or solutions to the problems that present themselves as creative alternatives for the conclusion of the study or research, among other possibilities.

The interactive processes of knowledge, analysis, studies, research, and individual or collective decisions can be called Active and Investigative Methodologies in Mathematics Education, whose purposes are to find solutions to problems and problematizations determined by the teacher or located by the students, as well as from thematic investigations established individually or collectively in the classroom. In this didactic procedure, the teacher acts as a facilitator or guide for the student to do research, reflect and decide for themselves, what to do in order to achieve the established objectives.

Thus, AIMMEs are based on creative ways of developing the learning process, using real or simulated experiences, aiming to find the most suitable conditions to successfully solve the challenges arising from the essential activities of social practice in different contexts in and outside the school that involve mathematical thoughts and practices. Likewise, we reiterate that the AIMME use problematization as a teaching strategy for learning, with the objective of reaching and provoking students in the face of a problematizing situation, so that they stop, examine, reflect, relate their historical development process and resignify their inventions or discoveries.

In the process of sociointeraction in search of the extent of these types of learning in the classroom, through the AIMME, problematization may put the students in touch with multiple information that allow for a production of integrated knowledge, mainly related to the solution of impasses referring to the obstacles which prevent the development of skills and competences for surveying and testing questions about new and old topics related to the knowledge that is to be built in the classroom. In this sense, learning through problematization constitutes a unique possibility for the active involvement of students in their own learning process.

We ask, however, what is the impact of these methodologies in the integral formation of the students? In this respect, teaching experiences have shown that students' engagement with new learning, comprehension, choice and interest is broadened, since this is the essential condition for expanding their possibilities of exercising freedom and autonomy in decision-making in different moments of the process that they experience, preparing them for a future personal and professional exercise.

This emphasis on teaching to lead students to learn from problematization or problematic situations is a recapturing of the foundations proposed by John Dewey (1859-1952), which has been adding experimental resignificances in multiple areas of knowledge, research and teaching with the fields of health, computing, environment and engineering. However, we have noticed that there is a certain absence of these didactic procedures in the formation of Mathematics teachers. On the other hand, the pedagogical proposals arising from the work of Paulo Freire (1921-1997) in the training course of Mathematics teachers who work in the field education have been resignified, especially when they focus on an encouraging invitation to the development of a problematizing education, supported by the understanding that educator and learner learn together in a dynamic relationship in which theory-oriented practice redirects this theory in a process of constant refinement, and that it is essential to explore reality in order to transform it.

One way of practicing these methodologies in the practice of the teacher of Mathematics Teacher Training and in his/her follow-up after leaving the course is through the elaboration and use of Basic Problems Units $(\mathrm{UBPs})^{1}$ and/or the elaboration, execution and evaluation of projects of thematic research. There is, however, a new question: what is a UBP? What is a project of thematic research?

Regarding the elaboration and use of Basic Units of Problematization (UBPs) in the teaching of Mathematics, we consider that it is a process of teaching and learning that involves the mobilization of thematic problematizations by exploring multiple sociocultural practices in search of identifying contributions for the construction of a network of conceptual and metacognitive meanings involved in solving real problems the goal of which is to lead students to the exercise of thinking. These practices to be explored in order to mobilize knowledge and mathematical practices in school should not be chosen at random and should, as far as it's possible, be a part of the collective needs of the student group itself, related to the sociocultural realities that are known or not known by themselves.

Choosing a practice does not necessarily imply that it should be tied exclusively to a discipline such as Mathematics or any other discipline. The nature of the themes to be mobilized for the classroom must be integral, that is, it must involve sociocultural aspects simultaneously related to social and disciplinary

${ }^{1}$ For further study on this theme, see Miguel and Mendes (2010), cited in the bibliography of this article. 
diversity, with a view to possible connections that can be made in the classroom. In this way, one can propose the solution of real problem-situations that afflict some communities in our society in the form of open problems to be proposed.

In the situations already experienced in teacher training courses in the scientific fields, as well as in the technological fields, we emphasize that it is possible to explore several socio-cultural practices linked to human activities, materialized in the form of projects of thematic research, in order to mobilize mathematical content in an integrated way, involving reality, mathematics and other disciplinary aspects. However, during the execution of the problematizing activities, there may appear solutions with imperceptible levels of depth. However, it is at these levels that several questions can be raised so that the discussions can reach the desired clarifications, giving rise to answers and theoretical explanations in a spontaneous and distinct way for each situation studied in the activities.

Such discussions may involve varying points of view according to the individual experiences of each participant and due to the integrated nature of the chosen practice. When constructing solutions to the problems proposed by the UBPs, students might be able to elaborate reflective theoretical formulations that will inevitably permeate the mathematical contents contemplated by the problematizing activity, but integrated with other types of not necessarily mathematical knowledge. Thus, we can enable students to develop other metacognitive skills beyond the mathematical ones, in a conscious way, i.e., students will know why they are studying certain contents and, in this way, the problematizing activity can become unforgettable for its participants and will certainly be invaluable for their conceptual development in Mathematics.

It is, therefore, through this type of process that occurs in the social interaction in the classroom that we defend the use of investigative practices, materialized in thematic problematizations, and composed of a set of open questions to be investigated as a methodological perspective of teaching and learning that introduces in Mathematics classes the principles defended by Abraham Moles (2012) on the sociodynamics of culture, according to which the knowledge of cultural facts contributes to the formulation of reflexive models about the scientific comings and goings around certain problems, and cause a dialectic process of understanding of the world through invention, adaptation and reinvention of languages that can give meanings to these possible understandings of the world.

In this sense, our experiences have shown that in the investigative practices, the student groups explore all the aspects that set up a given situation, make more detailed surveys and studies related to the themes, and seek information that leads them to the solutions to questions previously launched or that appear during the practices. Thus, the classroom is flipped and can be transformed into a classroom that experiences a practice centered on the investigation and problematization of socio-cultural objects in their mathematical connections.

\section{Final Note}

According to the inquiries, descriptions and reflective comments established throughout the writing of this article I repeat that the situations mentioned were part of the studies that I have been developing since the 1990s showed me how much this active way of approaching the teaching of mathematics in Basic Education and in the formation of teachers contributes decisively to an autonomous learning of those involved.

My affirmation takes into account the reflective descriptions and comments, both from the authors and myself, mentioned in this article. In this manner, it was possible to assert that the active methodologies were characterized as investigative practices in the teaching of mathematics (AIMME), mainly because it is an epistemological and methodological investment that values the conceptual and pedagogical potential of classroom interactions, subsidized by practices based on didactic teaching approaches that prioritize the direct investigative action of the students in search of achieving an autonomous study learning through these investigative actions.

Thus, I can therefore characterize the argumentative considerations established throughout the article as a reflexive writing from an action-intervention research exercise conducted directly in mathematics classes in the training of mathematics teachers and indirectly with students of Basic Education. The results obtained in these research experiments were analyzed from authors who base mathematical teaching proposals by means of investigative actions for learning reach, which contributed satisfactorily to the reflections that I presented. 


\section{Disclosure statement}

No potential conflict of interest was reported by the authors.

\section{Notes on contributors}

Iran Abreu Mendes - Universidade Federal do Pará and Programa de Pós-graduação em Educação em Ciências e Matemáticas - UFPA, Brasil.

\section{REFERENCES}

Anastasiou, L. G. C., \& Alves, L. P. (2007). Estratégias de ensinagem. In L. G. C. Anastasiou, \& L. P. Alves (Org.). Processos de ensinagem na universidade: pressupostos para estratégias de trabalho em aula (7. Ed.), Joinville, SC: Ed. UNIVILLE.

Anastasiou. L. G. C. (2014). Metodologia ativa, avaliação, metacognição e ignorância perigosa: elementos para reflexão na docência universitária. Revista Espaço para a Saúde, Londrina, 15(Suplemento n. 1).

Ausubel, D. P. (1978). Educational psychology. New York: Holt, Rinehart and Winston.

Barret, G. (1992). Pédagogie de l'expression dramatique (1. ed.), Montreal: Recherche en expression.

Barret. G. (1986). Essai sur la pédagogie de la situacion en expression dramatique et en éducacion. Montreal: Université de Montreal, Faculté des Sciences de l'éducacion.

Borasi, R. (1992). Learning mathematics through inquiry. Portsmouth, NH: Heinemann Educational Books.

Bruner, J. (1996). The culture of education. Massachusetts: Harvard University Press.

Dewey, J. (2007). Experience and education. New York: Penguin Group (USA).

Farias, C. A., \& Mendes, I. A. (2014). As culturas são as marcas das sociedades humanas [Cultures are the hallmarks of human societies]. In I. A. Mendes, \& C. A. Farias (Org.). Práticas socioculturais e Educação Matemática [Sociocultural Practices and Mathematics Education]. São Paulo: Ed. Livraria da Física, p. 15-48 (Col. Contextos da Ciência).

Freire, P. (1997). Pedagogia da autonomia: saberes necessários à prática educativa [Pedagogy of autonomy: knowledge necessary for educational practice]. Rio de Janeiro: Paz e Terra.

Lave, J., \& Wenger, E. (1991). Situated learning: legitimate peripheral participation. New York: Cambridge. https://doi.org/10.1017/CB09780511815355

Martins, A. (2002). Didáctica das Expressões [Didactics of the Expressions]. Lisboa: Universidade Aberta.

Mendes, I. A. (2009). Matemática e Investigação na sala de aula: tecendo redes cognitivas na aprendizagem. Editora Livraria da Física: São Paulo.

Mendes, I. A. (2013). The research as a principle for the teaching and learning of mathematics. Retrieved from http://www.sbem.com.br/ojs/index.php/ripem/article/view/54

Mendes, I. A. (2018). Active and Investigative Methodologies in Mathematical Education (AIMME): Research, learning and sociointeraction in Mathematics classes. Impresso. Belém/Brasil.

Mendes, I. A., \& Silva, C. A. F. (2017). Problematização de Práticas Socioculturais na Formação de Professores de Matemática [Problematization of Sociocultural Practices in Teacher Training in Mathematics]. Revista Exitus, Santarém/PA, 7(2), 100-126. https://doi.org/10.24065/2237-9460.2017v7n2ID303

Mendes, I. A., \& Silva, C. A. F. (2018). Problematization and Research as a Method of Teaching Mathematics. International Electronic Journal of Mathematics Education, 13(2), 41-55. https://doi.org/10.12973/iejme/2694

Miguel, A., \& Mendes, I. A. (2010). Mobilizing histories in mathematics teacher education: memories, social practices, and discursive games. ZDM Mathematics Education, 42, 381-392. https://doi.org/10.1007/s11858-010-0255-8

Moles, A. A. (2012). Sociodinâmica da cultura. [Sociodynamics of culture]. São Paulo: Perspectiva (Coleção estudos, 15).

Snow, C. P. (1995). As duas culturas e uma segunda leitura. [The two cultures and a second reading]. Trad. Geraldo Gerson de Souza. São Paulo: EDUSP, 1995.

http://www.iejme.com 